\title{
Development of a Method for Studying Thematic Content of Psychotherapy Sessions
}

\author{
P. Scott Richards \\ Brigham Young University - Provo, scott_richards@byu.edu \\ Susan D. Lonborg \\ Central Washington University
}

Follow this and additional works at: https://scholarsarchive.byu.edu/facpub

Part of the Student Counseling and Personnel Services Commons

\section{Original Publication Citation}

Richards, P. S. \& Lonborg, S. D. (1996). Development of a method for studying thematic content of psychotherapy sessions. Journal of Consulting and Clinical Psychology, 64, 701-711.

\section{BYU ScholarsArchive Citation}

Richards, P. Scott and Lonborg, Susan D., "Development of a Method for Studying Thematic Content of Psychotherapy Sessions" (1996). Faculty Publications. 3862.

https://scholarsarchive.byu.edu/facpub/3862 


\title{
Development of a Method for Studying Thematic Content of Psychotherapy Sessions
}

\author{
P. Scott Richards \\ Brigham Young University
}

\author{
Susan D. Lonborg \\ Central Washington University
}

\begin{abstract}
The authors developed a measure for categorizing the nature of the topic that clients and therapists discuss from moment to moment during psychotherapy. The Counseling Topic Classification System (CTCS) contains 55 topics and 8 emotional categories. It was used to code the thematic content of Donald Meichenbaum's and Hans Strupp's initial therapy sessions with a client named Richard. Our findings provided preliminary evidence that the CTCS is useful for coding the core topic of initial therapy sessions and that thematic content may be an important process and contextual variable. Methods are described for studying thematic content as a contextual variable and for presenting change process and discovery-oriented research findings so that they are more clinically meaningful.
\end{abstract}

In spite of a large and rather sophisticated research literature on counseling process and outcome, there is widespread agreement that this research has done little to influence or improve clinical practice (Barlow, 1981; Luborsky, 1972; Talley, Strupp, \& Butler, 1994). Because of concerns about this scientist-practitioner gap, two new types of process research, discovery-oriented and change-process research approaches, have recently been proposed (Greenberg, 1986; Mahrer, 1988; Rice \& Greenberg, 1984). Both discovery-oriented and change-process researchers advocate a multidimensional, events-based approach to the investigation of psychotherapy and change processes (Greenberg, 1986; Mahrer, 1988; Marmar, 1990; Rice \& Greenberg, 1984). As described by Marmar (1990), the "segments of interest are not random samples that often fail to capture the salient phenomena in the change process and are not

P. Scott Richards, Educational Psychology Department, Brigham Young University; Susan D. Lonborg, Department of Psychology, Central Washington University.

Portions of this article were presented in August 1994 at the 102nd Annual Convention of the American Psychological Association in I.os Angeles, California.

This research was partially supported by a faculty research grant from the College of Education at Brigham Young University and by a research grant from the faculty research committee at Central Washington University.

We express our appreciation to the graduate students who served on the CTCS research teams: Mike Lehman, Suzzane Stein, Doris Dant, Stacey McCullough, Kelly Bastian, Scott Bishop, Peggy Dehan, Terri Owens, and David Morgan at Brigham Young University; Roberta Cooper, Marc Sewell, Scott Pflieger, Denise Haegele, Lisa Barkus, Dominic Barraclough, Patricia Byers, Marli Dennison, and Colleen McCambridge at Central Washington University. We are grateful for the valuable ideas and suggestions they provided that helped us develop and refine the CTCS. We also thank Donald Meichenbaum and Hans 11. Strupp for giving of their time to participate in our study.

Correspondence concerning this article should be addressed to $P$. Scott Richards, Educational Psychology Department, 320D MCKB, Brigham Young University, Provo, Utah 84602. frequency counts, but rather they are change episodes or change events studied in context" (p. 266).

Discovery-oriented and change-process researchers believe that if psychothcrapy research is to become more clinically relevant and meaningful, it is crucial for researchers to take the therapy context into account (Greenberg, 1986; Heatherington, 1989; Talley et al., 1994). Greenberg (1986) recommended that researchers take into account four levels of context: content (e.g., child rearing concerns); speech acts (e.g., inform, advise, promise); episodes (e.g., challenging a specific irrational belief); and relationships (e.g., good working alliance). We believe that one important level of context is the thematic content of the session, or in other words, the type of problem or topic the client and therapist are discussing from moment to moment during psychotherapy. For example, are the client and therapist discussing the weather, academic problems, relationship difficulties, or the client's most recent suicide attempt?

The thematic content of psychotherapy sessions has not been studied very systematically to date (Heppner, Kivlighan, \& Wampold, 1992; Highlen \& Hill, 1984). Several studies have shown that there are gender, racial, and cultural differences in the presenting problems or topics clients disclose or are willing to disclose to therapists (e.g., Gim, Atkinson, \& Whiteley, 1990; June, Curry, \& Gear, 1990). A counseling process study by Cummings (1989) showed that the nature of the topic (interpersonal vs. intrapersonal problems) appeared to influence the types of verbal responses made by novice therapists. In addition, in a recent single-case study by Horowitz and colleagues (Horowitz et al., 1993), when the topic focused on the client's relationship with his decreased brother, the client manifested higher levels of emotionality and defensive control compared with occasions when he was discussing other topics.

Despite these few empirical indications that thematic content is a potentially important variable, the relation of topic with other process and outcome variables remains largely unknown. It also remains unclear how useful thematic content may be as a contextual variable. One reason for this lack of research on thematic content may be the lack of a widely accepted system 
for coding or classifying the nature of the topic that is being discussed from moment to moment during therapy. Heppner et al. (1992) recently discussed this deficiency and concluded that "research in counseling process would be enhanced by the development of a more sophisticated category system to classify the content of the counselor's and client's responses" (p. 325).

\section{Purpose of This Study}

In this article, we describe the Counseling Topic Classification System (CTCS; Lonborg, Richards, \& Owen, 1994; Richards \& Lonborg, 1991), a measure we developed for studying the thematic content of psychotherapy sessions. The major purposes of the study reported in this article were methodological in nature. Our first purpose was to begin exploring whether the CTCS is useful as a process measure of thematic content. Our second purpose was to explore whether including thematic content as a contextual variable enhances the clinical relevance of change-process and discovery-oriented research findings. Toward this cnd, we investigated the following four research questions: (a) Can judges use the CTCS to reliably categorize the nature of the topic (or topics) a client and therapist discuss from moment to moment during initial therapy sessions? (b) Does a therapist's theoretical orientation tend to be related to the nature of the problems or topics the therapist and client focus on during initial therapy sessions? (c) Do topic changes or patterns occur in initial therapy sessions that signal or are associated with clinically meaningful change events? (d) When analyzing and presenting change-process and discovery-oriented research data, can thematic content be included as a contextual variable in a way that enhances the clinical relevance and meaningfulness of the findings?

\section{Method}

\section{Development of the Topic Category System}

In 1990, we met to begin developing the CTCS. From (a) our clinical experience, (b) a literature search of research that has examined the nature, range, and frequency of problems clients' presented during therapy, and (c) a review of theory and research regarding the nature of emotions, we generated a list of common therapy topics, including eight categories of emotions (Plutchik, 1980) that clients may discuss in therapy. We also wrote definitions and therapy session examples of topics and emotions, and developed a rating form for judges to use when coding therapy sessions. During the next 3 years, several different rescarch teams coded many therapy session transcripts using the system. Feedback from the research teams led us to make many refinements to the system.

The CTCS provides researchers with a standardized method of classifying the nature of 55 topics and eight emotional dimensions as they occur from moment to moment in therapy. The CTCS is more broadgauged and less theoretically focused than are several methods for scoring content that have been developed from intrapsychic and interpersonal theoretical perspectives ( 2. g., Benjamin, 1986; Horowitz \& Rosenberg, 1994; Luborsky, 1976; Perry. Augusto, \& Cooper, 1989). One advantage of the CTCS is its breadth; researchers can code a wide range of topics using the CTCS. Another advantage of the CTCS is that it does not require the use of raters with extensive training in psychotherapy, nor does it require adherence to or familiarity with a particular theoretical viewpoint. The primary disadvantage of the CICS is its lack of specificity and depth. Researchers may need to develop more focused, detailed category systems for CTCS topics they wish to study in greater depth.

When using the CTCS, judges are instructed to code each topic they believe was mentioned during a talk turn or intentional meaning unit ': thus, multiple topics can be coded for each unit. The Appendix presents a list of the topics and emotional categories included in the CTCS. ${ }^{2} \mathrm{~A}$ category called ther topic is also provided so that researchers can add additional topics they may encounter that are not presently included on the CTCS.

\section{Therapy Session Transcripts}

We obtained typewritten transcripts of initial interviews conducted by Donald Mcichenbaum and Hans Strupp with a client named Richard. The therapy sessions were filmed by Psychological and Educational Films (Three Approaches to Psychotherapy III: Shostrom, 1986) for the purpose of demonstrating the respective therapeutic approaches of Meichenbaum and Strupp. ${ }^{3}$ Because the major purposes of our study were methodological in nature, and we were not concerned about drawing definite conclusions about actual therapeutic situations, we felt that the analog nature of the Meichenbaum and Strupp therapy sessions would not be a serious drawback in the present study.

\section{Measures}

In accord with recommendations of several in-session process researchers (e.g., Greenberg. 1986; Marmar. 1990), we examined what happened in the therapy sessions with Richard at multiple levels of process. We used the CTCS to categorize the nature of the topic or topics from moment to moment during the therapy sessions. The Classification System for Counseling Responses (CSCR; Highlen, Lonborg, Hampl, \& Lassiter. 1986) was used to code the counselor's and client's verbal response mode (e.g., cognitive restatement, agreement, affective self-description, insight, empathy) during the course of their therapy sessions. The Therapist Intentions List (Hill \& OGrady, 1985) was used to code the therapists' intervention rationales or intentions (e.g., get information, support. focus, clarify, change, challenge). The Client Experiencing Scale (EXP: Klein, Mathicu-Coughlan, \& Kiesler, 1986) was used to evaluate the quality of the client's emotional self-involvement in the therapy sessions. ranging from impersonal and emotionally detached (Stage 1) to personal and cmotionally aware and involved (Stage 7).

\section{Procedures}

Typewritten transcripts of the Meichenbaum and Strupp therapy sessions with Richard were purchased and permission to use these transcripts for research purposes was obtained from Psychological and Ed-

\footnotetext{
${ }^{1} \mathrm{An}$ intentional meaning anit is a response unit that "consists of an utterance which by itself conveys its own independent meaning when considered within the immediately surrounding text. In other words, a response is considered a unit when it can stand alone in transmitting an intelligible message" ( Highlen et al.. 1986. p. 12). Intentional meaning units are almost always shorter in length than talk turn units.

${ }^{2}$ A copy of the CTCS manual can be obtained by writing to P. Scott Richards.

${ }^{3}$ This film series also shows Aaron T. Beck having a therapy session with Richard. We invited Beck to participate in our study, but we did not receive a reply. Because we do not have complete data available for Beck's session, we describe only Meichenbaum's and Strupp's session in the present report.
} 
ucational Films (Corona Del Mar, CA). Two judges independently unitized the written transcripts into talk turn and intentional meaning units. Unitization agreement rates for the talk turn transcripts were $100 \%$, and for the intentional meaning unit transcripts they were .98 (Strupp) and .99 (Meichenbaum).

A research team composed of six masters-level students in counseling psychology at Brigham Young University was trained in the use of the CTCS by P. Scott Richards between November 1993 and April 1994. During May and June 1994, after their CTCS training was completed, these six judges coded the Meichenbaum and Strupp session transcripts using the CTCS.

A research team composed of two master's-level students in counseling psychology at Central Washington University (CWU) was trained by Susan D. Lonborg in the use of the CSCR between January 1994 and the end of April 1994. During May and June 1994, the two graduate students and Susan D. Lonborg used the CSCR to code the Strupp and Meichenbaum session transcripts, which, as required by the CSCR, had been unilized into intentional meaning units. These data were later collapsed into talk turn units to make them compatible with the therapist intentions and client experiencing data. Reliabilities for each combination of the three raters were computed; kappa coefficients for the CSCR ratings for the three pairs of judges ranged from .74 to $.95(M=.86)$.

Meichenbaum and Strupp were sent written transcripts of their session with Richard and were asked to use the Therapist Intentions List to code their intentions for each verbal response (talk turn) they had made during their therapy session with Richard. Using the EXP, P. Scott Richards rated the mode experiencing level and, when appropriate, the peak experiencing level manifested by the client during each talk turn unit in the Meichenbaum and Strupp sessions.

\section{Data Analysis}

All five levels of process data were analyzed using a computer program called Luura (Version 1.3): A Program for Analyzing Counseling Irocess Data (Richards \& Owen, 1992). The Laura program provides for each therapy session (or any part of a session) (a) kappa coefficients (Cohen, 1960) for each pair of judges, (b) an overview of which process categories were reliably coded (i.e., agreed on by at least 2 of 3 judges) for each talk turn or coding unit; (c) a process category frequency and percentage breakdown; and (d) a graphical overview of which process categories were reliably coded for each talk turn or coding unit. Because kappas are artificially low when the frequency distributions across categories are skewed (our data had categories with very low and very high rates of usage), we also computed simple percentage of agreements across all categories and all talk turns for each pair of CTCS raters. Finally, we computed chi-square tests of independence to determine whether Meichenbaum and Strupp differed significantly in the frequency that they talked about various topics with Richard.

Searching for topic changes and patterns. Using the graphical overview of the reliably coded topics for each talk turn and the typewritten therapy transcripts, we both independently looked for changes and patterns in thematic content of each therapy session. The topic changes and patterns in Meichenbaum's and Strupp's therapy sessions were quite distinctive, and we agreed $100 \%$ on the frequency of topic changes, where the topic changes occurred. and the length of each topic pattern. ${ }^{4}$

Identifying change events. A variety of criteria can be used in psychotherapy research to identify potentially important change events (Greenberg, 1986: Rice \& Greenberg, 1984); for example, clicnt requests for help, client emotional experiencing (e.g., crying), therapist verbal responses (e.g., confrontation), client ratings of helpful in-session interventions, and therapist ratings of helpful in-session interventions could all potentially help identify change events. Clusters of patient and therapist markers may often be needed to accurately identify important change events in therapy. Ultimately, the "acid test" of whether a significant change event has occurred in therapy must be outcome data that documents that change has occurred.

In the present study, we searched for possible change cvents by looking for places in the therapy sessions where Meichenbaum and Strupp indicated that their intentions were to promote insight, challenge, promote change, or reinforce change. According to the Therapist Intentions List, all of these therapist intentions share the goal of attempting to promote changes in clients' thinking. feelings, or behavior. After identifying places in the transcripts where it was the intention of the therapist to promote change, we examined what happened at the other levels of process in an attempt to understand why the therapist was attempting to promote change at this point of the session. Because we did not have in-session outcome data regarding the therapeutic impact of the therapists' interventions in these sessions, we cannot be certain that the potential change cvents we identificd actually represented genuine change events for the client.

\section{Results}

For Meichenbaum's session, kappa coefficients for the CTCS talk turn data ranged from .44 to $.56(M=.49)$, and overall percentage of agreements ranged from $53.5 \%$ to $67.4 \%(M=$ $58.4 \%$ ). For Strupp's session, kappas for the CTCS talk turn data ranged from .40 to $.48(M=.44)$, and overall percentage of agreements ranged from $54.5 \%$ to $60.7 \%(M=57.9 \%)$.

There were 138 talk turn units in Meichenbaum's therapy session and 125 in Strupp's session. For the CTCS data, in $52.2 \%$ of Meichenbaum's session and $56.0 \%$ of Strupp's session, all three judges agreed that the client and therapist were discussing only one topic at a time. In $36.2 \%$ of Meichenbaum's session and $36.8 \%$ of Strupp's session, all three judges agreed that the therapist and client were discussing two topics at a time. In the remainder of these two sessions ( $11.6 \%$ of Meichenbaum's session and $7.2 \%$ of Strupp's session ), the judges perceived that three topics (and rarely, four topics) at a time were being discussed.

The percentage of talk turns in which at least one topic was reliably coded for the therapy sessions were $91.3 \%$ (Mcichenbaum) and $92.8 \%$ (Strupp). This indicates that for both sessions, for over $90 \%$ of the time two or more judges agreed on the nature of at least one of the topics on a given talk turn. The percentage of agreement for "one-topic" talk turns for the therapy sessions were $83.3 \%$ (Meichenbaum) and $88.6 \%$. (Strupp). This indicates that on those occasions when all three judges coded only one topic for a given talk turn $(52.2 \%$ and $56.0 \%$ of the time, respectively, for Meichenbaum's and Strupp's sessions), on over $80 \%$ of these occasions two or more judges agreed on the nature of the topic that had occurred. Thus, despite the low overall kappas and percentage of agreements. these data reveal that the judges did tend to reliably agrec on what the main topic was during each talk turn unit over the course of the therapy sessions.

The percentage of agreement for "two-topic" talk turns for the therapy sessions were $34.0 \%$ (Meichenbaum) and $45.7 \%$

\footnotetext{
${ }^{4}$ Although we achieved $100 \%$ agreement on these two transcripts, we do not believe that topic changes will be as easy to reliably identify in all therapy transcripts.
} 
(Strupp). The percentage of agreement for "three-topic" talk turns for the therapy sessions were $18.8 \%$ (Meichenbaum) and $22.2 \%$ (Strupp). This indicates that on those occasions when all three judges coded two or more topics for a given talk turn, on less than $50 \%$ of these occasions two or more judges agreed on the nature of all of the topics that had occurred. These data indicate that the judges had difficulty reliably coding more than one topic on a given talk turn.

The CTCS data revealed that there were differences in the frequency that various counseling topics were discussed during Meichenbaum's and Strupp's therapy sessions. When we excluded unreliable data from our analysis, we found that Strupp devoted $60.9 \%(N=81)$ of his therapy session to the discussion of Richard's relationships, compared with Meichenbaum's $32.2 \%(N-46)$ for relationships, $\chi^{2}(1)=21.8, p<.005 .^{5}$ Meichenbaum spent $27.3 \%(N-39)$ of his session talking about Richard's emotions and $8.4 \%(N=12)$ of his session discussing suicide, compared with Strupp's $12.8 \%(N=17)$ on emotions, $\chi^{2}(1)=8.05, p<.005$ and $0 \%$ on suicide, $\chi^{2}(1)=$ $9.72, p<.005$. Meichenbaum spen $7.0 \%(N=10)$ of his session in discussions of coping and problem management, compared with Strupp's $0.1 \%(N=1), \chi^{2}(1)=5.47, p<.05$. Meichenbaum used $21.7 \%(N=31)$ of his session talking about Richard's self-identity, compared with Strupp's $12.8 \%$ ( $N=$ 17), $\chi^{2}(1)=3.20, p<.10$.

When we examined the graphical overview of the CTCS data provided by the Laura computer program (Richards \& Owen, 1992), we found that the focus of the thematic content changed or shifted emphasis seven times during Meichenbaum's therapy session and five times in Strupp's session. Following Greenberg's (1986) levels of context terminology, we adopted the term topic episode to describe these rather distinct topic patterns or communicative routines. Table 1 provides a summary of what was discussed during each topic episode in Meichenbaum's and Strupp's therapy sessions.

From our examination of the therapist intention data, we concluded that two potential change events occurred during Meichenbaum's therapy session, and one potential change event occurred during Strupp's session. In Table 2 it can be seen that in Meichenbaum's session, Change Event 1 (anger management) had its beginnings during Topic Episode 3 as Meichenbaum attempted to get Richard to talk about and intensify his anger (Talk lurn 58). After succeeding at this, Meichenbaum shifted the topic to problem management (Talk Turn 60) and began to focus on helping Richard examine the consequences of his uncontrolled expressions of anger and on identifying alternative, more functional ways of managing and expressing his anger. The anger management change event was marked by Meichenbaum's change of topic to problcm management (Talk Turn 60) and by Meichenbaum's intentions to promote insight (Talk Turns 58 and 60 ), challenge Richard (Talk Turns 64 and 66), and promole change (Talk Turns 68 and 70 ).

Change Event 2 (suicide prevention) in Meichenbaum's session occurred when he changed the topic from Richard's "female shopping list" and asked Richard to describe his depression (Talk Turn 104). Richard began behaviorally describing his depression and briefly mentioned that he sometimes has thoughts about committing suicide (Talk Turn 105). Meichenbaum immediately asked Richard to tell him about the suicidal thoughts and plan (Talk Turn 106). When Richard finished describing his plan, Meichenbaum asked Richard what keeps him from committing suicide (Talk Turn 120) and reinforced Richard's desire not to commit suicide (Talk Turn 122). The beginning of the suicide prevention change event was marked by a change in topic to suicide (Talk Turns 105 and 106) and was concluded by Meichenbaum's efforts to instill hope, provide support, and promote insight and change (Talk Turns 120 and 122).

In Table 3 it can be seen that Change Event 1 (identifying the client's cyclical maladaptive pattern) in Strupp's session occurred when, after discussing Richard's relationship with his ex-wife for the first half of the session, Dr. Strupp changed the topic by asking Richard whether he has had similar kinds of relationships at other times in his life (Talk Turn 69). This change in topic led Richard to begin discussing his attitudes and expectations toward women he has dated in the past (Talk Turn 70). During this discussion, Dr. Strupp made several attempts to help Richard see the similarities between the problems in his relationship with his ex-wife and the problems in his relationships with other women. The change event of cyclical maladaptive pattern was marked by a change in topic to relationships with other women (Talk Turns 69 and 70) and by Strupp's intentions to promote insight ( Talk Turns 69, 73, 75, 77, and 79).

\section{Discussion}

Because of the skewed frequency distributions across the CTCS categories observed in the Meichenbaum and Strupp sessions, the percentage of agreements should be viewed as more valid estimates of interrater agreement than the kappa coefficients in the present study. Nevertheless, the overall percentage of agreements for the CTCS ratings were also quite low, as were the percentage of agreements for multiple-topic talk turns. However, the CTCS judges did show high levels of agrecment when rating one-topic talk turns, and they did agree on what onc of the counseling topics was on over $90 \%$ of the talk turns.

We belicve that the difficulty the judges had in reliably coding more than one topic on a talk turn reflect, in part at least, the nature and role of thematic content in therapy sessions. From our clinical experience and the data in the present study, we believe that during therapy sessions, especially the first few sessions, clients often introduce multiple potential topics. It is not possible for therapists to respond to cvery potential topic clients mention. From their theoretical orientation and clinical experience, therapists judge which topics are important. On this basis, therapists respond to and encourage clients to pursue clinically important topics in greater length and detail.

Skilled therapists, we believe, Icarn to tune out the thematic noise (peripheral topics) and focus on the thematic signal (core topics) during therapy sessions. The fact that the CTCS judges

\footnotetext{
${ }^{5}$ The $N_{\mathrm{s}}$ associated with the chi-square analyses refer to the number of times a CTCS topic was reliably coded for a therapy session. The total number of reliably coded topics was 143 in Meichenbaum's session and 133 in Strupp's session.
} 
Table

Topic Episode Descriptions and Summaries for Meichenbaum's (M.) and Strupp's (S.) Therapy' Sessions with Richard (R.)

\begin{tabular}{|c|c|c|c|}
\hline $\begin{array}{l}\text { Topic } \\
\text { episode }\end{array}$ & Description & Topic or topics & $\begin{array}{l}\text { No. of talk } \\
\text { turns }\end{array}$ \\
\hline \multicolumn{4}{|c|}{ Meichenbaum's session } \\
\hline 1. & $\begin{array}{l}\mathrm{R} \text {. informs } M \text {. that he is depressed and angry over his recent divorce and provides details } \\
\text { about the divorce. }\end{array}$ & Relationship (ex-wife) & 11 \\
\hline 2. & $\begin{array}{l}\text { R. mentions that he has been going to counseling and that he is changing from someone who } \\
\text { used to be angry, rude, and difficult to get along with to someone who is getting better at } \\
\text { expressing his feelings and who is more caring and kind. }\end{array}$ & Self-identity & 14 \\
\hline 3. & $\begin{array}{l}\text { R. expresses his anger and depression about his divorce and his desire to eliminate these } \\
\text { feelings. M. and R. explore R.'s relationship with his ex-wife, his anger toward her. his } \\
\text { desire to express it to her, and how such expressions will affect her. }\end{array}$ & $\begin{array}{l}\text { Relationship (ex-wife). } \\
\text { anger, and self- } \\
\text { identity }\end{array}$ & 34 \\
\hline 4. & $\begin{array}{l}\text { M. tries to get } R \text {. to focus on more constructive ways to express his anger. R. 's emotional } \\
\text { experiencing (anger) is quite intense during the first half of this topic episode and he yells } \\
\text { at M ("shut up!"). M. keeps focusing on examining other more functional ways R. can } \\
\text { express his anger. }\end{array}$ & $\begin{array}{l}\text { Problem-management } \\
\text { and anger }\end{array}$ & 28 \\
\hline 5. & $\begin{array}{l}\text { M. asks } \mathrm{R} \text {. to tell him about his depression. R. describes how lonely he is and how much he } \\
\text { wants a new female companion. He then describes a "shopping list" of qualities he has for } \\
\text { women he dates. M. listens briefly and then ends this topic episode by again asking R. to } \\
\text { tell him about his depression. }\end{array}$ & $\begin{array}{l}\text { Relationship (dating), } \\
\text { depression, and } \\
\text { loneliness }\end{array}$ & 16 \\
\hline 6. & $\begin{array}{l}\text { R. describes his depression behaviorally and briefly mentions he sometimes has thoughts of } \\
\text { suicide. M. immediately asks R. about the suicidal thoughts, and R. behaviorally describes } \\
\text { his suicide plan (to shoot himself). M. reinforces R.'s desire not to commit suicide, } \\
\text { acknowledges how much R. has been through recently, reinforces R.'s desire to change. } \\
\text { and tries to convey hope. }\end{array}$ & Suicide & 18 \\
\hline 7. & $\begin{array}{l}\text { M. concludes session with a summary of R.'s relationship issues and the need he has to } \\
\text { further look at his anger and depression issues. }\end{array}$ & $\begin{array}{l}\text { Relationships (in } \\
\text { general) }\end{array}$ & 17 \\
\hline \multicolumn{4}{|c|}{ Strupp's session } \\
\hline 1. & $\begin{array}{l}\text { S. asks what brings } R \text {. to counseling. R. describes divorec, financial and emotionat } \\
\text { consequences of divorce, and details about problems in the relationship with his ex-wife. } \\
\text { R. eludes to feeling that he did not live up to his ex-wife's expectations. }\end{array}$ & Relationship (cx-wife) & 34 \\
\hline 2. & $\begin{array}{l}\text { S. asks } R \text {. to go back to the topic of not living up to his ex-wife sexpectations. R. reports } \\
\text { fecling put down and angry, describing specific incidents in detail. S. asks R. whether he is } \\
\text { aware of anything he did to aggravate the relationship. }\end{array}$ & Relationship (ex-wife) & 34 \\
\hline 3. & $\begin{array}{l}\text { S. inquires whether R. has had similar experiences in other relationships. R. describes his } \\
\text { attitude toward women (e.g. "sex objects") prior to his marriage. R. also discusses his } \\
\text { unrealistic expectations (e.g.. looking for the perfect woman). }\end{array}$ & $\begin{array}{l}\text { Relationship (other } \\
\text { women \& ex-wife) } \\
\text { and self-identity }\end{array}$ & 23 \\
\hline 4. & $\begin{array}{l}\text { R. initially sidetracks by asking how a football team is going to do, then admits that he did } \\
\text { not expect } S \text {. to invite him to ask questions. After R. mentions a list of future-oriented } \\
\text { questions, S. focuses on clarifying R.'s job status and inquires whether anger has been a } \\
\text { problem on the job. R. suggests that his problems stem from his childhood and wishes that } \\
\text { he had gotten therapy sooner. }\end{array}$ & $\begin{array}{l}\text { Job loss. relationship } \\
\text { (female co-worker), } \\
\text { anger. and self- } \\
\text { identity }\end{array}$ & 18 \\
\hline 5 & $\begin{array}{l}\text { S. inquires about whether there was any one thing in R.'s childhood that he atributes his } \\
\text { problems to. R. refers to lack of affection from his alcoholic parents and that he was an } \\
\text { only child with few friends. S. acknowledges that R.'s relationship difficulties in present } \\
\text { are connected to his parental and childhood peer relationships. }\end{array}$ & $\begin{array}{l}\text { Relationship (parents, } \\
\text { childhood peers) } \\
\text { and anger }\end{array}$ & 16 \\
\hline
\end{tabular}

were able to identify and reliably code at least one topic per talk turn (but not more) suggests that they were able to reliably code the thematic signal as it flowed and shifted throughout the therapy sessions, but not the thematic noise. We believe this was the case because the core topic was easier for the judges to recognize because the therapists and client focused on it longer and discussed it more explicitly and clearly in comparison to the pe. ripheral topics.

At times it may also be the case that multiple-topic talk turns do represent clinically important phenomena. For example, perhaps multiplc-topic talk turns are sometimes instances of double-level messages in which the client is discussing one topic or issue but alluding vaguely to some other important but threatening issue. Perhaps at these points of ambiguity CTCS researchers need to incorporate data from other modalities (e.g., nonverbal cues such as tone of voice, facial expressions, and body language ) in order to understand and reliably distinguish thematic signal from thematic noise. In future research with the CTCS it would be worthwhile to investigate whether CTCS raters who are working from both videotapes and transcripts can achieve higher levels of agreement on multiple-topic talk turns than can raters working only from transcripts. Our hypothesis that the thematic signal (core topic) can be reliably coded by CTCS raters but the thematic noise (peripheral topics ) cannot, should also be empirically tested. One set of raters could be asked to follow the CTCS rater instructions we 
Table 2

Anger Management and Suicide Prevention Change Events That Occurred During Topic Episodes

4 and 6 of Meichenbaum's Therapy Session With Richard

\begin{tabular}{lllll}
\hline TT & CTCS topic & $\begin{array}{l}\text { Therapist } \\
\text { intention }\end{array}$ & Therapist VRM & Client VRM \\
\hline 58 & $\begin{array}{l}\text { Relationship (EW) } \\
\text { Emotion (anger) }\end{array}$ & $\begin{array}{l}\text { Get into } \\
\text { Behavior } \\
\text { Insight }\end{array}$ & $\begin{array}{l}\text { Request nonspecific info } \\
\text { Provide info }\end{array}$ \\
59 & Emotion (anger) & exp & Request for clarification \\
\hline
\end{tabular}

Topic Episode 4 (anger management change event)

\begin{tabular}{|c|c|c|c|}
\hline 60 & $\begin{array}{l}\text { Problem manage } \\
\text { Lmotion (anger) }\end{array}$ & $\begin{array}{l}\text { Get info } \\
\text { Behavior } \\
\text { Insight }\end{array}$ & Request nonspecific info \\
\hline 61 & Problem manage & & \\
\hline 62 & $\begin{array}{l}\text { Problem manage } \\
\text { Fmotion (anger) }\end{array}$ & $\begin{array}{l}\text { Get info } \\
\text { Clarify } \\
\text { Behavior }\end{array}$ & $\begin{array}{l}\text { Request nonspecific info } \\
\text { Provide info }\end{array}$ \\
\hline 63 & Problem manage & & \\
\hline 64 & Unreliable topic & $\begin{array}{l}\text { Get info } \\
\text { Behavior } \\
\text { Challenge }\end{array}$ & Interpretation \\
\hline 65 & Unreliable topic & & \\
\hline 66 & Ambiguous topic & $\begin{array}{l}\text { Get info } \\
\text { Cathart } \\
\text { Challenge }\end{array}$ & Interpretation \\
\hline 67 & Ambiguous topic & & \\
\hline 68 & Problem manage & $\begin{array}{l}\text { Get info } \\
\text { Behavior } \\
\text { Change }\end{array}$ & Request nonspecific info \\
\hline 69 & Ambiguous topic & & \\
\hline 70 & Problem manage & $\begin{array}{l}\text { Get info } \\
\text { Behavior } \\
\text { Change }\end{array}$ & $\begin{array}{l}\text { Request nonspecific into } \\
\text { Reinforce change }\end{array}$ \\
\hline 71 & Emotion (love) & & \\
\hline 72 & $\begin{array}{l}\text { Emotion (love) } \\
\text { Emotion (anger) }\end{array}$ & $\begin{array}{l}\text { Get info } \\
\text { Behavior } \\
\text { Feelings }\end{array}$ & $\begin{array}{l}\text { Request for clarification } \\
\text { Confrontation }\end{array}$ \\
\hline 73 & Unreliable topic & & \\
\hline 74 & Problem manage & $\begin{array}{l}\text { Get info } \\
\text { Support } \\
\text { Behavior }\end{array}$ & Request nonspecific info \\
\hline
\end{tabular}

Behavioral SD

Topic Lpisode 6 (suicide prevention change event)

\begin{tabular}{|c|c|}
\hline 104 & Emotion (depression) \\
\hline 105 & $\begin{array}{l}\text { Emotion (depression) } \\
\text { Suicide }\end{array}$ \\
\hline 106 & Suicide \\
\hline $\begin{array}{l}107 \\
108\end{array}$ & $\begin{array}{l}\text { Suicide } \\
\text { Unreliable topic }\end{array}$ \\
\hline 109 & Suicide \\
\hline & Suicide \\
\hline
\end{tabular}

Get info

Clarify

Feelings

Get info

Clarify

Feelings

Get info

Clarify

Feelings

Get info

Clarify

Feelings
Affective SD

Cognitive SD

Request for clarification

Request nonspecific info

Rehavioral SD

Cognitive SD

3

Request nonspecific info

Cognitive SD

3

Request specific info

Cognitive SD

2 
Table 2 (continued)

\begin{tabular}{|c|c|c|c|c|c|}
\hline $\mathrm{TT}$ & CTCS topic & $\begin{array}{l}\text { Therapist } \\
\text { intention }\end{array}$ & Therapist VRM & Client VRM & $\begin{array}{c}\text { Client } \\
\exp \end{array}$ \\
\hline 112 & No topic & $\begin{array}{l}\text { Get info } \\
\text { Clarify } \\
\text { Feelings }\end{array}$ & Minimal encourager & & \\
\hline 113 & Suicide & & & $\begin{array}{l}\text { Cognitive SD } \\
\text { Behavioral SD }\end{array}$ & 2 \\
\hline 114 & Suicide & $\begin{array}{l}\text { Get info } \\
\text { Clarify } \\
\text { Feelings }\end{array}$ & Empathy & & \\
\hline 115 & Suicide & & & $\begin{array}{l}\text { Agreement } \\
\text { Nonself descr }\end{array}$ & 2 \\
\hline 116 & Unreliable topic & $\begin{array}{l}\text { Behaviors } \\
\text { Feelings } \\
\text { Challenge }\end{array}$ & Empathy & & \\
\hline $\begin{array}{l}117 \\
118\end{array}$ & $\begin{array}{l}\text { Unreliable topic } \\
\text { Unreliable topic }\end{array}$ & $\begin{array}{l}\text { Get info } \\
\text { Clarify } \\
\text { Behaviors }\end{array}$ & Minimal encourager & Cognitive SD & 2 \\
\hline 119 & Suicide & & & $\begin{array}{l}\text { Cognitive SD } \\
\text { Nonself descr }\end{array}$ & 2 \\
\hline 120 & Suicide & $\begin{array}{l}\text { Get info } \\
\text { Clarify } \\
\text { Hope } \\
\text { Insight } \\
\text { Change }\end{array}$ & $\begin{array}{l}\text { Request nonspecific info } \\
\text { Self-involvement in counseling process }\end{array}$ & & \\
\hline $\begin{array}{l}121 \\
122\end{array}$ & $\begin{array}{l}\text { Suicide } \\
\text { Self-identity } \\
\text { Emotion (depression) }\end{array}$ & $\begin{array}{l}\text { Support } \\
\text { Hope } \\
\text { Change }\end{array}$ & $\begin{array}{l}\text { Empathy } \\
\text { Self-involvement } \\
\text { Interprelation }\end{array}$ & Cognitive SD & 3 \\
\hline
\end{tabular}

Note. Therapist intentions that appear in boldface type indicate intentions that were viewed by the researchers as possible change event markers. $\mathrm{TT}=$ talk turn; $\mathrm{VRM}=$ verbal response mode; Client $\mathrm{Exp}=$ client experiencing level; $\mathrm{Info}=$ information; manage $=$ management; $\mathrm{EW}=$ ex-wifc; OW $=$ other women; $C W=$ coworker; $D=$ dating: $S D=$ self-description; Self-Exp $(I .1)=$ self-expericncing level $($ Level 1$) ;$ Exp $C / C$ Rel $=\operatorname{exploring}$ client-counsclor relationship: Nonself descr $=$ non-self-description; Behaviors = therapist's intention was to identify and give feedback about clicnt's behavior: Feelings - therapist's intention was to identify and intensify client's feelings.

used, and another set of raters could be asked to identify what they believe to be core topics and peripheral topics.

\section{Theoretical Orientation and Thematic Focus}

Hans Strupp is a time-limited psychodynamic therapist and views clients problems as disturbances in interpersonal relationships (Shostrom, 1986; Strupp \& Binder, 1984). A central task of the psychotherapist, according to Strupp, is to identify and work with clients' cyclical maladaptive pattern, in other words, their central interpersonal problem (Strupp \& Binder, 1984). Therapists do this by exploring and establishing connections and similarities between clients' behavior and experiences in past relationships, current relationships, and the current therapeutic relationship. Given his theoretical orientation, therefore, it is understandable why Strupp talked about Richard's interpersonal relationships more frequently than he did all other topics combined.

Donald Meichenbaum, a cognitive-behavioral therapist, is perhaps best known for his development of stress inoculation training, a treatment approach designed to help clients cope with and manage problematic life events (Meichenbaum, 1985). Therapists do this by helping clients explore and become more aware of the contributions of their thoughts, behaviors, beliefs, and feelings to their problems and by teaching them new coping skills (Meichenbaum, 1985; Shostrom, 1986). Given his theoretical orientation, therefore, it is understandable why Meichenbaum talked more about how Richard could better cope with and manage his problems of anger, depression, and suicidal ideation and less about Richard's relationships than did Strupp.

Tentatively, therefore, our findings suggest that therapists' theoretical orientation may influence which topics are discussed and the amount of time topics are focused on during therapy sessions. Of course, more research is needed with a greater number of therapists and clients in actual therapy situations before we can have confidence that this is the case.

\section{Topic Changes}

The finding that there were multiple changes in the focus of the thematic content in the therapy sessions was of interest. It is not surprising that in these two initial, intake therapy sessions, multiple changes in the focus of the counseling topic occurred. We believe that it is common for therapists in the first few sessions with a client to cover a wide range of topics as they assess and diagnosis the client. We would predict that as therapy progresses beyond the initial assessment interviews, fewer counsel- 
Table 3

Culical Maladaptive Pattern Change Event That Occurred in Topic Episode 3 During Strupp's Therapy Session With Richard

\begin{tabular}{llllll}
\hline TT & CTCS topic & $\begin{array}{l}\text { Therapist } \\
\text { intention }\end{array}$ & Therapist VRM & Client VRM & $\begin{array}{c}\text { Clicnt } \\
\text { exp }\end{array}$ \\
\hline 67 & $\begin{array}{l}\text { Relationship (EW) } \\
\text { Emotion (anger) } \\
\text { Relationship (EW) } \\
\text { Fmotion (anger) }\end{array}$ & $\begin{array}{l}\text { Get info } \\
\text { Clarify }\end{array}$ & Empathy & & \\
& & $\begin{array}{l}\text { Ngreement } \\
\text { Behavioral SD } \\
\text { Cognitive SD }\end{array}$ & 3,4 \\
\hline
\end{tabular}

Topic Episode 3 (cyclical maladaptive pattern change event)

\begin{tabular}{|c|c|c|c|c|c|}
\hline 69 & Self-identity & Get info & Request specific info & & \\
\hline 70 & Relationship (OW) & & & $\begin{array}{l}\text { Behavioral SD } \\
\text { Cognitive SD }\end{array}$ & 3 \\
\hline 71 & Relationship (OW) & Get info & Empathy & & \\
\hline 72 & Rclationship (OW) & & & Agreement & 3 \\
\hline 73 & Relationship (OW) & Insight & $\begin{array}{l}\text { Request specific info } \\
\text { Empathy }\end{array}$ & & \\
\hline 74 & Relationship (OW) & & & Agreement & 3 \\
\hline 75 & Ambiguous topic & $\begin{array}{l}\text { Insight } \\
\text { Get info }\end{array}$ & Request specific info & & \\
\hline 76 & $\begin{array}{l}\text { Relationship (OW) } \\
\text { Self-identity }\end{array}$ & & & $\begin{array}{l}\text { Disagreement } \\
\text { Affective SD } \\
\text { Behavioral SD } \\
\text { Cognitive SD }\end{array}$ & 3,4 \\
\hline 77 & Relationship (EW) & Insight & $\begin{array}{l}\text { Empathy } \\
\text { Interpretation }\end{array}$ & & \\
\hline 78 & Relationship (EW) & & & Agreement & 3 \\
\hline 79 & Relationship (OW) & $\begin{array}{l}\text { Get info } \\
\text { Insight }\end{array}$ & $\begin{array}{l}\text { Request specific info } \\
\text { Interpretation }\end{array}$ & & \\
\hline 80 & Ambiguous topic & & & Cognitive SD & 2 \\
\hline 81 & Self-identity & Challenge & Request specific info & & \\
\hline 82 & $\begin{array}{l}\text { Relationship (EW) } \\
\text { Self-identity }\end{array}$ & & & Cognitive SD & 2 \\
\hline 83 & Relationship (OW) & Cognitions & Empathy & & \\
\hline 84 & $\begin{array}{l}\text { Relationship (OW) } \\
\text { Relationship (EW) }\end{array}$ & & & $\begin{array}{l}\text { Agreement } \\
\text { Cognitive SD } \\
\text { Behavioral plans }\end{array}$ & 2 \\
\hline
\end{tabular}

Note. Therapist intentions that appear in boldface type indicate that these intentions were viewed by the researchers as possible change markers. $T T=$ talk turn; $V R M=$ verbal response mode; Client exp = client experiencing level; info = information; $\mathrm{EW}=$ ex-wife; $\mathrm{OW}=$ other women; $\mathrm{SD}=$ self-description: $\mathrm{Cogni}$ tions $=$ therapist' $s$ intention was to identify maladaptive thoughts.

ing topics will be introduced and focused on in a given session. In fact, one important indicator of effective psychotherapy (particularly time-limited therapy) may be a narrowing of thematic focus as therapy progresses. This hypothesis could readily be tested using the CTCS.

From the therapist intentions data and other process data, it seemed quite clear that some of the topic changes observed in the therapy sessions did represent clinically important patient markers (Greenberg, 1986; Marmar, 1990). For example, in Meichenbaum's session, the change in topic to problem (anger) management (Talk Turn 60 in Table 2) marked the beginning of an intervention by Meichenbaum that appeared designed to move Richard away from simply venting his anger to examining how he could take more responsibility for learning to appropriately manage and express his anger. Later in this session, the change in topic from a discussion of Richard's dating rclation- ships to his depression (Talk Turn 104 in Table 2) marked the beginning of an important suicide risk assessment and prevention intervention. In Strupp's session, the change in topic from Richard's relationship with his ex-wife to a discussion of other relationships in Richard's life (Talk Turn 69 in Table 3) marked the beginning of an intervention by Strupp that appeared designed to help Richard gain insight into his cyclical maladaptive pattern.

Although we certainly do not believe that all changes in topic represent important markers. our findings suggest that some may be. Changes in topic may signal the beginning of one meaningful unit of therapeutic interaction and the end of another. We believe, therefore, that searching for changes in topic in therapy session transcripts represents one strategy process researchers can use when seeking to identify important change events in therapy. 


\section{Levels of Context and Topic Episodes}

Initially, we had assumed that the CTCS data would only provide us with information about Greenberg's ( 1986) first level of context (i.e., the content level of the therapy sessions). However, as we read the transcripts and examined the graphical, sequential overview of the CTCS data for each therapy session, we noticed rather clear shifts and patterns in thematic focus in the sessions. We realized that perhaps these distinctive patterns of thematic focus were evidence of Greenberg's ( 1986) third level of context (i.e., the episode level of context).

Greenberg ( 1986 ) referred to episodes as "meaningful units of therapeutic interaction which, according to the therapeutic approach being used, are designed to achieve an intermediate therapeutic goal" ( $p .5$ ). We believe that the patterns of thematic interaction that occurred in the Meichenbaum and Strupp therapy sessions, which are described in Table 1, certainly represent meaningful units of therapeutic interaction and are deserving of the label topic episodes.

\section{Studying Change Events in the Context of Topic Episodes}

Once we understood the context at the topic episode level at a given point in a therapy session, it became easier to understand the change events that had occurred in Meichenbaum's and Strupp's therapy sessions. For example, during the problem (anger) management change event (Change Event 1) in Meichenbaum's session, the therapist intentions data signaled the fact that at this point in the session Meichenbaum was attempting to promote insight and change (Talk Turns 60, 64, 66, 68, 70 in Table 2).

However, without the context of the topic episode, we would have been unable to understand what type of insight and change Meichenbaum was trying to promote. We would also have been unable to understand why Meichenbaum chose that particular moment in therapy to attempt to promote insight and change. The context of the topic episode helped us better understand what lype of change Meichenbaum was trying to promote (i.e., help Richard learn to better manage and express his anger) and why he may have attempted this intervention at that point in the therapy session (i.e., in the previous topic episode he had heard Richard talk about how he wants to scream, hit, and hurt people when he feels angry).

We believe, therefore, that it is difficult for researchers to fully understand change events that occur in therapy unless they are studied in the context of the topic episodes within which they occurred. Talley et al. (1994) stated that "to be clinically meaningful, research must provide a therapeutic context for its interpretation" (p. 255). Certainly, the topic that is being discussed at a given moment in a therapy session provides an important therapeutic context for clinicians as they seek to understand their clients. We believe that including thematic content as a contextual variable when analyzing and reporting change-process and discovery-oriented research could enhance the meaning and clinical relevance of such research.

\section{Limitations of the Study}

A number of limitations of the present study should be kept in mind. First, our conclusions about the usefulness of the CTCS and the importance of thematic content in psychotherapy and psychotherapy research are based on a small database. Furthermore, these two initial therapy sessions were somewhat artificial in nature considering the educational purpose for which they were conducted. Because of this, we cannot safely generalize our findings to actual therapeutic siluations. Because the only criterion we used for deciding whether a change event had occurred in the therapy sessions was the therapist intentions data (we did not have outcome data from the client), we cannot be confident that the events we studied actually caused the client to change. Finally, as is often the case in discovery-oriented and change-process research, most of our data were analyzed in an exploratory, rather subjective manner. Clearly, much more research on the CICS and on the role of thematic content in psychotherapy is needed before we will know how useful this line of research will be for change-process and discovery-oriented researchers.

\section{Conclusions}

Despite the limitations of our study, we believe it does make several methodological contributions that could help bridge the gap between psychotherapy research and practice (Talley et al., 1994 ). Our study presents preliminary information about a new process system for categorizing the thematic content of therapy sessions. The CTCS is useful for coding the core topic that is being discussed from moment to moment in therapy, and it may be useful for exploring how variations in thematic content are related to client, therapist, outcome, and other process variables. The CTCS may also have potential for helping discovery-oriented and change-process researchers identify topic changes or thematic markers that signal the beginning of potentially important change events (Greenberg, 1986; Marmar, 1990). The CTCS may also be useful as a system to help researchers take topic into account as a I evel 3 (episode) contextual variable (Greenberg, 1986). Including the thematic episode level of context in their research could help psychotherapy researchers better understand change events that occur in therapy.

Finally, Talley and his colleagues (Talley et al., 1994) have pointed out that there is a need for methods that allow psychotherapy researchers to provide more information about the clinical context of their research when they present their findings. Our study illustrates a method that we believe could be useful in this regard. In our Tables 2 and 3, all levels of process data for selected topic episodes and change events are summarized sequentially. These tables, along with the topic episode summaries in Table 1, allow researchers to take the clinical context more fully into account, for they provide rich detail about what happened at all levels of process before, during, and after a change event. When publishing in journals, topic episode summaries and segments of therapy sessions that are of interest could be published. and researchers could make copies of tables that summarize all levels of process for the complete session or 
sessions available to interested professionals. ${ }^{6}$ Such tables could also be a valuable addition to multiuser therapy transcript archives that have been called for by several researchers (e.g., Marmar, 1990).

${ }^{6}$ Copics of all five levels of process data presented sequentially for Meichenbaum's and Strupp's sessions are available on request from $P$. Scott Richards.

\section{References}

Barlow, D. H. (1981). On the relation of clinical research to clinical practice: Current issues, new direction. Jotunal of Consulting and Clinical Psychology: 49. 142-155.

Benjamin, L. S. (1986). Operational definition and measure of dynamics shown in the stream of free association. Psychiatry, 49, 104-109.

Cohen, J. A. (1960). A coefficient of agreement for nominal scales. Educational and Psychological Measurement, 20, 37-46.

Cummings. A. L. ( 1989). Relationship of client problem type to novice counselor response modes. Journal of Connseling Psychology. 36 , 331-335.

Gim, R., Atkinson, D., \& Whiteley, S. (1990). Asian-American acculturation, severity of concerns, and willingness to see a counselor. Jomal of Counseling Psichology 37, 281-285.

Greenberg, L. (1986). Change process research. Journal of Consulting and Clinical Psychology, 54, 4-9.

Heatherington, L. (1989). Toward more meaningful clinical research: Taking context into account in coding psychotherapy interaction. Psychotherapy, 26, 436-447.

Heppner, P. P.. Kivlighan, D. M.. \& Wampold, B. (1992). Research design in counseling. Pacific Grove, CA: Brooks Cole.

Highlen, P. S., \& Hill, C. F. (1984). Factors affecting client change in individual counseling: Current status and theoretical speculations. In S. D. Brown \& R. W. Lent (Eds.), Jlandbook of counseling psychology (pp. 334-396). New York: Wiley.

Highlen, P. S., Lonborg, S. D., Hampl. S. P., \& Lassiter, W. L. (1986). Classification System for Counseting Responses (CSCR) manual. Unpublished manuscript, Ohio State University.

Hill, C. E., \& O'Grady, K. E. (1985). List of therapist intentions illustrated in a case study and with therapists of varying theoretical orientations. Journat of Counseling Psycholog!, 32, 3-22.

Horowitz, L. M., \& Rosenberg. S. E. (1994). The consensual response psychodynamic formulation: Part 1. Method and research results. Psvchotherapy Research, 4, 222-233.

Horowitz., M. J., Stinson, C., Curtis, D., Ewert, M., Redington. D., Singer, J.. Bucci, W. Mergenthaler, E., Milbrath, C., \& Ilartley, D. (1993). Topics and signs: Defensive control of emotional expression. Journal of Consulting and Clinical Psychology, 61, 421-430.
June, L. N., Curry, B. P., \& Gear, C. L. (1990). An 11-year analysis of black students' experience of problems and use of services: Implications for counseling professionals. Journal of Counseling Psychology, $37,178-184$

Klein, M. H.. Mathicu-Coughlan, P., \& Kiesler, D. J. (1986). The Experiencing scales. In L. Greenberg \& W. Pinsof (Eds.), The psychotherapeutic process: A research handbook (pp. 21-72). New York: Guilford Press.

lonborg, S. D., Richards, P. S.. \& Owen, I. E. (1994). The Counseling Topic (lassification Sistem (CTCS) mamial. Unpublished manuscript, Department of Educational Psychology, Brigham Young University.

Luborsky, I. ( 1972). Research cannot vet influence clinical practice. In $A$. Bergin \& H. Strupp (Eds.), Changing frontiers in the science of pswhoherapy (pp. 120-126). Chicago: Aldine.

Luborsky, I.. (1976). Helping alliances in psychotherapy: The groundwork for a study of their relationship to its outcome. In J. L. Claghorn (Ed.). Successful pswhotherapy (pp. 92-116). New York: Brunner/ Mazel.

Mahrer, A. (1988). Discovery-oriented research. American Pspchologist, 43, 694-702.

Marmar, C. R. (1990). Psychotherapy process research: Progress, dilemmas, and future directions. Journal of Consulting and Clinical Psychology: 58, 265-272.

Meichenbaum, D. (1985). Stress inocutation training. New York: Pergamon Press.

Perry, J. C.. Augusto. F., \& Cooper, S. H. (1989). The assessment of psychodynamic conflicts: 1 . The reliability of an idiographic method. Psuchiatry, 52, 284-301.

Plutchik, R. (1980). Emotion: A psychoevolutonary synthesis. New York: Harper \& Row

Rice, L. N., \& Greenberg. L. S. (1984). Patterns of change: Intensive analysis of psychotherapl process. New York: Guilford Press.

Richards, P. S., \& Lonborg. S. D. (1991, April). A discovery-oriented coding syitem for psychotherapy research. Paper presented at the annual meeting of the Western Psychological Association. San Francisco.

Richards, P. S., \& Owen, S. (1992). Laura (Version 1.3): A program for andlyzing counsding process data [computer program]. Department of Educational Psychology. Brigham Young University. Provo, Utah.

Shostrom. E. L. (1986). Three approaches to psuchotherapy III [transcript of film]. Corona Del Mar. CA: Psychological and Educational Films.

Strupp, H. H., \& Binder, J. L. (1984). Pswehotherapy in a new key: A gutide to time-limited dinamic psychotherapy: New York: Basic Books.

Talley, P. F., Strupp. H. H.. \& Butler. S. F. ( 1994). Prwchotherapy research and practice: Bridging the gap. New York: Basic Books. 


\section{Appendix}

\section{List of Counseling Topic Classification System Topics}

1. Abuse

(a) physical

(b) sexual

(c) emotional

2. Academics (school)

3. Alcoinol-other drug use

(a) alcohol use

(b) drug use

4. Career/life planning

(a) decision-making

(b) employment-job issues

(c) avocational-leisure

5. Child-rearing/parenting issues

6. Discrimination

7. Eating behavior

8. Finances

9. Individual differences

(a) age

(b) disability

(c) gender

(d) racial-ethnic

(e) religious

(f) spiritual

(g) sexual orientation

10. Interpersonal concerns

(a) alienation-loneliness

(b) conflict

(c) loss

(d) shyness

11. I egal issues

12. Living conditions

13. Moral/ethical issues

14. Performance concerns

(a) specch anxiety

(b) test anxiety

(c) perfectionism

15. Physical health

16. Political issues
17. Problem management

(a) coping

(b) decision making

(c) problem-solving

18. Relationships
(a) parents
(b) siblings
(c) children
(d) other relative
(e) family (other)
(f) romantic-dating
(g) fricnds
(h) marriage-partnership
(i) roommate
(j) teacher
(k) supervisor-boss
(l) colleagues-co-workers
(m) counselor
(n) client
19. Self-esteem/inferiority
20. Self-injury/suicide
21. Sexuality
22. Sleep disturbances
23. Social issues
24. Stress
25. Emotions
(a) affiliation (love. liking)
(b) rejection (disgust, dislike)
(c) destruction (rage. anger)
(d) protection (panic, anxiety)
(e) self-affirmation (joy, serenity)
(f) reintegration (grief, depression)
(g) orientation (surprise, confusion)
(h) exploration (anticipation, curiosity)
26. Ambiguous topic
27. No topic
28. Other topic $(A-Z)$

Received February 16, 1995

Revision received September 22, 1995

Accepted October 6,1995 